\title{
Prognostic factors in metastatic gastric cancer: results of a population-based, retrospective cohort study in Ontario
}

\author{
Matthew Dixon • Alyson L. Mahar • \\ Lucy K. Helyer · Jovanka Vasilevska-Ristovska • \\ Calvin Law • Natalie G. Coburn
}

Received: 19 June 2014/ Accepted: 28 October 2014/Published online: 25 November 2014

(c) The International Gastric Cancer Association and The Japanese Gastric Cancer Association 2014

\begin{abstract}
Background Stage IV gastric cancer is lethal, and little population-based research on prognostic factors has been performed in low-incidence countries. Therefore, we investigated the consistency of the associations of patient, disease and healthcare system factors identified in previous population-based research to understand their generalizability to other low-incidence populations.

Methods A population-based, retrospective cohort study of patients diagnosed with Stage IV gastric cancer in Ontario between 1 April 2005 and 31 March 2008 was performed. Kaplan-Meier methodology and the log-rank test were used for bivariate analysis. Multivariate Cox proportional hazard regression was performed. Hazard ratios (HRs) and $95 \%$ confidence intervals (CIs) are presented.
\end{abstract}

M. Dixon and A. L. Mahar equal first authorship.

\section{Dixon}

Department of Surgery, Maimonides Medical Center, Brooklyn, NY, USA

M. Dixon · A. L. Mahar · J. Vasilevska-Ristovska · C. Law ·

N. G. Coburn $(\bowtie)$

Division of Surgical Oncology, Odette Cancer Centre,

Sunnybrook Health Sciences Centre, Sunnybrook Research

Institute, Suite T2-60, 2075 Bayview Ave, Toronto,

ON M4N 3M5, Canada

e-mail: natalie.coburn@sunnybrook.ca

\section{A. L. Mahar}

Department of Public Health Sciences, Queen's University,

Kingston, ON, Canada

L. K. Helyer

Department of Surgery, Dalhousie University, Halifax, NS,

Canada
Results On multivariate analysis, patient, disease and healthcare system factors were independent predictors of survival. Increasing age per 10 years (HR 1.07; $95 \%$ CI 1.02-1.10), a tumor located in the gastroesophageal junction (HR 1.09; $95 \%$ CI $0.94-1.27$ ) or middle of the stomach (HR 1.14; $95 \%$ CI 0.97-1.35), presence of carcinomatosis (HR 1.61; $95 \%$ CI 1.42-1.83) and a larger burden of metastatic disease (2-3 sites of metastatic disease: HR 1.17; $95 \%$ CI 1.03-1.32; $\geq 4$ sites: HR 1.69; $95 \%$ CI 1.30-2.20) were associated with worse prognosis. Female gender, receipt of surgery, chemotherapy and radiotherapy and treatment from a high-volume, gastric cancer specialist were all associated with significantly better prognosis. In addition, there was evidence of significant geographic variation in survival.

Conclusion This study provides supporting evidence for patient, disease and healthcare system prognostic factors in metastatic gastric cancer. Future work investigating the

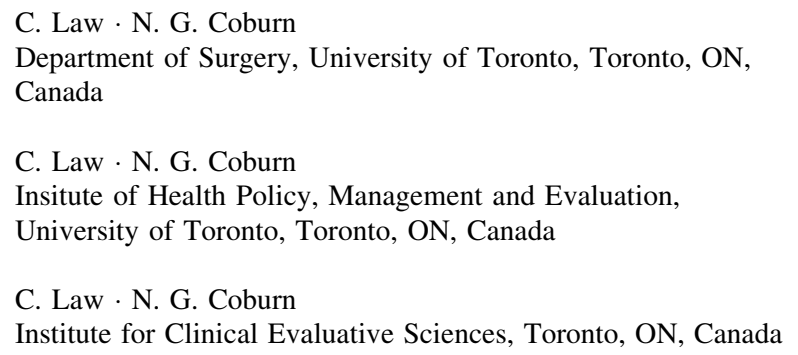


role of emerging molecular and biologic information will need to take these established prognostic factors into consideration.

Keywords Metastatic cancer · Prognostic factor

\section{Introduction}

Gastric cancer is the fourth most commonly diagnosed cancer worldwide and the second leading cause of cancerrelated mortality $[1,2]$. TNM stage is the cornerstone of prognostication in gastric cancer and used to guide treatment decision-making [3, 4]. Stage IV disease $\left(\mathrm{T}_{\text {any }} \mathrm{N}_{\text {any- }}\right.$ $\mathrm{M}_{1}$ ) is diagnosed in 35-55\% of gastric cases in lowincidence countries such as the USA and Canada, and this preponderance of noncurative disease contributes substantially to its dismal survival rate $[5,6]$. Median diseasespecific survival in metastatic disease has been estimated to be approximately 10 months [3] and overall 5-year survival estimated to be $3-5 \%[6,7]$.

Due to the rarity of this disease and a lack of staging data, little population-based research to investigate prognosis in patients with metastatic gastric cancer in North America or Europe has been performed [8-11]. In the few studies that have been completed using large databases, tumor grade, age, sex, ethnicity/race, marital status and receipt of treatment were identified as important prognostic factors [8-11]. These studies have been limited by missing information on important variables, such as tumor location, extent of metastatic disease, comorbidities and socioeconomic status. Furthermore, the impact of physician volume is missing and diminishes our understanding of the disease and its management at the population level.

Therefore, we aimed to use a large, population-based Canadian administrative data set supplemented by individual chart review data to expand on existing knowledge in the prognosis of Stage IV gastric cancer. Demonstrating the generalizability of prognostic factors across populations is essential to providing evidence of the consistency of the associations [12]. Replication of results is a key step in prognostic factor research, one that is often underperformed [12]. In doing so, we aimed to confirm the prognostic value of disease, patient and healthcare system factors identified in previous population-based studies, while examining the value of additional prognostic factors such as the primary tumor location, burden of metastatic disease and care from a high-volume gastric cancer specialist. The purpose of this study was to determine which factors may explain worse survival to help refine prognostication and to identify any potentially modifiable factors that might be targeted to improve patient outcomes in the future.

\section{Methods}

A retrospective, population-based cohort study and chart review of gastric cancer patients in Ontario, Canada, was performed. Ontario has over 13 million inhabitants, making it the most populous province in Canada. This project received Research Ethics Board approval at Sunnybrook Health Sciences Centre and adhered to privacy and confidentiality regulations of the Institute for Clinical Evaluative Sciences (ICES). The purpose of this study was to test the generalizability of prognostic factors identified in other low-incidence, population-based databases, as well as examine the association with survival of several prognostic factors not yet explored in the literature [12].

\section{Study population}

Patients were identified through the Ontario Cancer Registry (OCR), a registry of incident cancer cases in the province [13, 14]. Patients were staged according to the AJCC 7th edition [4] using radiology, pathology and clinical information collected during a primary chart review. Patients were excluded if they were younger than 18 years, older than 99 years, diagnosed with a nonadenocarcinoma cancer, had tumors in the mid to upper esophagus, were missing geographic residence information, did not have a valid Ontario Health Insurance Plan number (OHIP), were diagnosed on autopsy or death certificate only, or had nonmetastatic disease.

\section{Data collection and sources}

A comprehensive province-wide chart review (hospital charts, including radiology, endoscopy, operative and consultation notes) was performed and linked to the following administrative data sets held by ICES: OHIP, the Canadian Institute of Health Information-Discharge Abstract Database (CIHI-DAD) and the Registered Persons Database (RPDB). The chart review provided clinical disease data, such as the stage, symptoms and primary information on treatment strategies. OHIP contains physician billing claims and provided information on treatment modalities [15]. CIHI-DAD contains data on procedures for all in- and outpatient services provided at provincial institutions and provided supplemental information on the interventions provided to the cohort [15]. 


\section{Outcome definition}

Overall survival was the primary outcome of this study and measured using the date of death from the OCR, and death due to any cause was considered an event. Survival was measured from the date of diagnosis to death. Individuals were followed from their date of diagnosis until the end of our follow-up period (31 March 2010).Patients were censored if they did not experience the event (death) in this time period. Because there was staggered entry into the cohort (dates of diagnosis across a 2-year period), each patient had differing amounts of follow-up, with a minimum of 3 years of follow-up for all survivors. The OCR provided information on the vital status of Ontarians from the Ontario Registrar General.

Disease, patient and healthcare system prognostic factors

Information in endoscopy reports was used to define tumor location. Locations included the gastroesophageal junction (GEJ), proximal stomach, middle stomach, distal stomach, entire stomach or unknown. Results from radiology and pathology reports were used to determine the location and number of metastatic sites. The locations were categorized as follows: distant lymph node(s), carcinomatosis and/or ascites, liver, retroperitoneal, lung, bone or ovarian. Other sites of metastasis were rare and not analyzed. The number of metastatic sites was calculated as the sum of all unique distant organ locations where cancer was found. If a patient had more than one site of metastasis within an organ as categorized above, it only counted once toward the number of metastatic sites. Patients for whom an M1 diagnosis had been made, but specific sites of metastasis were not provided, were categorized as unknown.

In addition to age (modeled as a continuous variable on multivariate analysis) and sex, the following prognostic factors have been identified in the literature as being related to survival in metastatic gastric cancer: comorbidity, socioeconomic status (SES) [16], rurality [17], tumor location, location and number of metastatic sites, geographic region of residence, treatment (surgery, chemotherapy and radiotherapy) and receipt of care from a highvolume specialist. Comorbidity was measured using the Deyo modification of the Charlson score [18, 19]. In Ontario, all health services are provided by a single-payer system run by the provincial government, and healthcare planning, spending and delivery are organized into 14 Local Health Integrated Networks (LHINs) (http://www. lhins.on.ca/home.aspx). Patients were assigned to a geographic region categorized into LHINs using their postal codes. These regions were labeled 1-14. Physician billing codes were used to identify which patients had received a gastrectomy (partial or total, with or without a multivisceral resection) and chemotherapy and to define receipt of radiotherapy. Gastric cancer patient volume for each physician within each specialty (surgeon, medical oncologist, radiation oncologist) was calculated over a 7-year time period (1 April 2003-31 March 2010), and physicians were categorized into volume quartiles by specialty. Volume classifications were created such that one quarter of patients fell into each category. By our definition, a highvolume surgeon performed an average of at least 3.5 gastrectomies/year, a high-volume medical oncologist saw on average at least 6.7 gastric cancer patients/year, and a highvolume radiation oncologist saw on average at least 15.8 gastric cancer patients/year. Receipt of care or a consultation from at least one of the three high-volume specialists defined above was considered a "yes" for the high-volume consultation variable.

Statistical analysis

Median survival was calculated using Kaplan-Meier methods [20]. Bivariate and multivariate survival analyses were performed using Cox-proportional hazards methods to produce a hazard ratio. Hazard ratios and their $95 \%$ confidence intervals provided an estimate of the relative rate of death between two comparator groups. Values $>1$ indicate an increased rate of death, and values $<1$ indicate a decreased rate of death. Backward selection modeling was used to explore whether or not a priori prognostic factors selected from the literature describing survival for metastatic gastric cancer patients in low-incidence countries were independent predictors of survival in our data set, using a cutoff $p$ value of 0.05 to determine which predictors stayed in the model. The assumptions of proportional hazards were assessed by including a time-dependent variable in the model for each covariate [21]. All analyses were performed using SAS 9.2, copyright 2008 (Cary, NC, USA). Cell sizes containing $<6$ patients were suppressed because of the privacy and confidentiality regulations of ICES and the Ontario Privacy Commissioner.

\section{Results}

In Ontario, 2,516 patients had a registered diagnosis of gastric cancer during the study period. Figure 1 provides an overview of the cohort selection process. Table 1 provides a description of the final cohort of 1,433 patients $(57 \%)$ with metastatic disease. Median survival for the cohort was 6.2 months (Table 2) and is shown in Fig. 2. Bivariate relationships between all disease, patient and healthcare 
Fig. 1 Cohort selection process

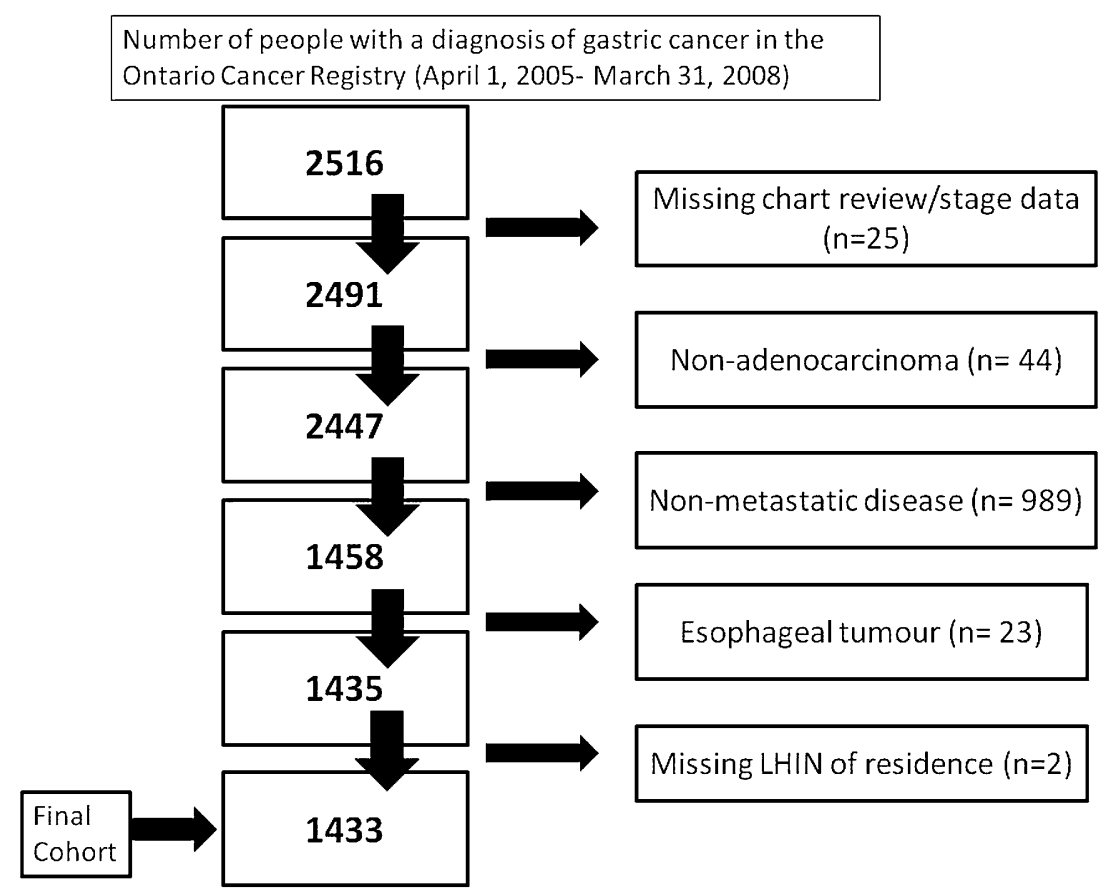

system factors and survival were statistically significant, with the exception of the presence of ovarian or distant lymph node metastases, comorbidities, and median household income (Table 3). Strong associations with an increased rate of death were also documented for older age (HR 1.47; $95 \%$ CI 1.30-1.67), tumors of the entire stomach (HR 1.41; $95 \%$ CI 1.15-1.71), a large number of organs involved with distant disease (HR 2.12; $95 \%$ CI 1.65-2.71), and the presence of carcinomatosis or ascites (HR 1.48; $95 \%$ CI 1.33-1.66). The strongest predictors of survival on bivariate analysis were related to the healthcare system. Receipt of a gastrectomy was associated with a nearly $60 \%$ reduction in rate of death (HR 0.42; $95 \%$ CI $0.37-0.47)$; receipt of chemotherapy was associated with a $46 \%$ reduced rate of death (HR $0.54 ; 95 \%$ CI $0.49-0.61$ ) and radiotherapy with a $37 \%$ reduced rate of death (HR $0.5895 \%$ CI $0.51-0.65)$. A significantly increased rate of death was also noted in 1 of the 14 LHINs (HR 2.12; $95 \%$ CI 1.43-3.11). Consultation with or treatment from a highvolume gastric cancer specialist was associated with an almost $40 \%$ reduction in rate of death (HR 0.61; $95 \% \mathrm{CI}$ 0.54-0.68).

On multivariate analysis, age, sex, tumor location, presence of carcinomatosis or ascites, number of organs involved with metastatic disease, treatment strategy, geographic region of residence and consultation with a highvolume specialist all remained independent predictors of survival (Table 4). The effects of all prognostic factors were reduced when the other variables were included in the model. Increased age was significantly associated with an increased rate of death of $7 \%$ for every 10 years (HR 1.07;
$95 \%$ CI 1.02-1.10). Individuals with a tumor located in the gastroesophageal junction (HR 1.09; $95 \%$ CI 0.94-1.27) or the middle stomach (HR 1.14; $95 \%$ CI 0.97-1.35) were also at a significantly increased rate of death. The presence of carcinomatosis remained a strong prognostic factor, after controlling for all other factors, and was associated with a $60 \%$ increased rate of death (HR 1.61; $95 \%$ CI 1.42-1.83). In addition, the more organs involved with metastatic disease, the greater was the rate of death. Patients with four or more anatomic sites involved with metastatic disease had a significantly higher rate of death than patients with only one site (HR 1.69; $95 \%$ CI 1.30-2.20).

Compared to men, women had a $19 \%$ reduced rate of death (HR 0.82; $95 \%$ CI 0.73-0.92). Patients with tumors located in the proximal stomach had a significantly decreased rate of death compared to patients with a tumor located in the distal stomach (HR 0.83; $95 \%$ CI 0.68-1.02). The five healthcare system prognostic factors remained the strongest prognostic factors in metastatic gastric cancer. Receipt of gastrectomy was associated with an almost $60 \%$ reduction in rate of death (HR $0.43 ; 95 \%$ CI 0.38-0.49), receipt of chemotherapy was associated with a $45 \%$ reduction in rate of death (HR 0.56; $95 \%$ CI 0.49-0.64), and receipt of radiotherapy was associated with a $20 \%$ reduction in rate of death (HR 0.77; $95 \%$ CI 0.68-0.88). While these results support an association between treatment strategies and survival, they do not confirm causation and must be interpreted with caution, given that the selection of patients for treatment is unclear. Understanding which patients are appropriate to select for which combination of treatment and palliation to incur 
Table 1 Description of the cohort $(n=1433)$

\begin{tabular}{ll}
\hline Variable & $\begin{array}{l}\text { Number of patients } \\
(\%)\end{array}$ \\
\hline
\end{tabular}

Patient characteristics

Age (mean)

67.5 years (range 20-97)

Gender

$934(65)$

Charlson score

0

1,279 (89)

82 (6)

$\geq 2$

Median income

Lowest income

Quintile 2

Quintile 3

Quintile 4

Highest income

Rurality

Urban

Disease characteristics

Tumor location

Gastroesophageal junction

390 (27)

Proximal stomach

139 (10)

Middle stomach

229 (16)

Distal stomach

476 (33)

Entire stomach

$134(9)$

$65(5)$

Unknown

700 (49)

435 (30)

179 (12)

53 (4)

Unknown

Location of metastasis

Carcinomatosis or ascites

$880(61)$

Distant lymph nodes

$714(50)$

423 (29)

137 (10)

104 (7)

$92(6)$

32 (2)

31 (2)

Abdominal wall

$<6$

$<6$

Prostate

Healthcare system characteristics

High-volume gastric cancer specialist consultation

477 (33)

Gastrectomy

527 (37)

Chemotherapy

$615(43)$

Radiotherapy
Table 1 continued

\begin{tabular}{ll}
\hline Variable & $\begin{array}{l}\text { Number of patients } \\
(\%)\end{array}$ \\
\hline Local health integration network (LHIN) & \\
1 & $81(6)$ \\
2 & $79(5)$ \\
3 & $77(5)$ \\
4 & $167(12)$ \\
5 & $72(5)$ \\
6 & $122(9)$ \\
7 & $151(11)$ \\
8 & $211(15)$ \\
9 & $152(11)$ \\
10 & $53(4)$ \\
11 & $127(9)$ \\
12 & $41(3)$ \\
13 & $78(5)$ \\
14 & $22(2)$ \\
\hline
\end{tabular}

optimal benefits is necessary before the survival impact of these treatment modalities can be concluded. The effect of specialist volume was greatly reduced on multivariate analysis. This may signify that high-volume specialists see a different case mix of patients, and controlling for their characteristics in addition to treatment provided explains the majority of the provider impact on outcomes for patients with metastatic disease. Heterogeneity in rate of death for metastatic gastric cancer patients existed across the province, even after controlling for different treatment and patient characteristics that may have explained differences in survival, and it remained a significant prognostic factor.

\section{Discussion}

In low-incidence countries, the average oncologist will face more incurable cases of gastric cancer than curative. Our study is consistent with other Western studies, finding more than $50 \%$ of gastric cancer cases are metastatic at diagnosis. On average, these patients have a dismal prognosis, and in our study median survival was only 6.2 months. This study supports previous findings that a number of patient, disease and healthcare system prognostic factors are associated with survival in this terminally ill population, some of which may be modifiable. Increasing age and male sex were associated with worse prognosis, and variation in rates of death were documented across tumor locations and geographic regions. In addition, the presence of carcinomatosis and/or ascites and the extent of metastatic disease were identified as significant predictors of 
Table 2 Comparing survival among patient, disease and healthcare system variables (log-rank test)

\begin{tabular}{|c|c|c|c|c|}
\hline Variable & Category & $\begin{array}{l}\text { Median } \\
\text { survival } \\
\text { (months) }\end{array}$ & $95 \% \mathrm{CI}$ & $p$ value \\
\hline \multicolumn{5}{|l|}{ Patient characteristics } \\
\hline \multirow[t]{3}{*}{ Age (years) } & $<65$ & 8.6 & $7.5-9.6$ & $<0.0001$ \\
\hline & $65-74$ & 6.8 & $5.2-7.8$ & \\
\hline & $>74$ & 4.1 & $3.4-4.8$ & \\
\hline \multirow[t]{2}{*}{ Sex } & Female & 6.3 & $5.4-7.6$ & 0.1473 \\
\hline & Male & 6.0 & $5.3-6.9$ & \\
\hline \multirow[t]{3}{*}{ Charlson score } & 0 & 6.4 & $5.8-7.2$ & 0.0706 \\
\hline & 1 & 4.2 & $2.4-6.0$ & \\
\hline & $\geq 2$ & 5.1 & $2.8-7.6$ & \\
\hline \multirow[t]{5}{*}{ Median income } & $\begin{array}{l}\text { Lowest } \\
\text { income }\end{array}$ & 5.5 & $4.7-6.9$ & 0.6212 \\
\hline & $\begin{array}{l}\text { Quintile } \\
2\end{array}$ & 6.2 & $5.2-7.6$ & \\
\hline & $\begin{array}{l}\text { Quintile } \\
3\end{array}$ & 6.5 & $4.8-7.9$ & \\
\hline & $\begin{array}{l}\text { Quintile } \\
4\end{array}$ & 5.9 & $4.8-7.4$ & \\
\hline & $\begin{array}{l}\text { Highest } \\
\text { income }\end{array}$ & 7.0 & $5.6-8.1$ & \\
\hline \multirow[t]{2}{*}{ Rurality } & Rural & 5.2 & $4.2-7.2$ & 0.0309 \\
\hline & Urban & 6.2 & $5.7-7.0$ & \\
\hline \multicolumn{5}{|l|}{ Disease characteristics } \\
\hline \multirow[t]{6}{*}{ Tumor location } & GEJ & 7.0 & $5.6-8.2$ & 0.0124 \\
\hline & Proximal & 6.6 & $4.8-8.6$ & \\
\hline & Middle & 5.0 & $3.9-5.9$ & \\
\hline & Entire & 4.3 & $3.1-5.6$ & \\
\hline & Distal & 7.4 & $6.0-8.2$ & \\
\hline & Unknown & 7.6 & $3.4-10.8$ & \\
\hline \multirow{4}{*}{$\begin{array}{l}\text { Number of } \\
\text { metastatic sites }\end{array}$} & 1 & 8.6 & $7.6-9.7$ & $<0.0001$ \\
\hline & $2-3$ & 4.8 & $4.3-5.3$ & \\
\hline & $\geq 4$ & 3.5 & $2.4-4.8$ & \\
\hline & Unknown & 5.3 & $2.7-9.9$ & \\
\hline \multirow{2}{*}{$\begin{array}{l}\text { Distant LN } \\
\text { metastasis }\end{array}$} & No & 6.1 & $5.3-7.1$ & 0.5600 \\
\hline & Yes & 6.2 & $5.3-7.2$ & \\
\hline \multirow{2}{*}{$\begin{array}{l}\text { Carcinomatosis or } \\
\text { ascites }\end{array}$} & No & 8.8 & $7.7-10.0$ & $<0.0001$ \\
\hline & Yes & 5.0 & $4.3-5.4$ & \\
\hline \multirow[t]{2}{*}{ Liver metastasis } & No & 7.1 & $6.1-7.9$ & $<0.0001$ \\
\hline & Yes & 5.0 & $4.3-5.7$ & \\
\hline \multirow{2}{*}{$\begin{array}{l}\text { Retroperitoneal } \\
\text { metastasis }\end{array}$} & No & 6.4 & $5.8-7.1$ & 0.0276 \\
\hline & Yes & 5.5 & $5.0-6.4$ & \\
\hline \multirow[t]{2}{*}{ Lung(s) metastasis } & No & 6.3 & $5.7-7.0$ & 0.0169 \\
\hline & Yes & 4.9 & $3.9-7.4$ & \\
\hline \multirow{2}{*}{$\begin{array}{l}\text { Bone(s) } \\
\text { metastasis }\end{array}$} & No & 6.3 & $5.7-7.1$ & 0.0098 \\
\hline & Yes & 4.6 & $3.2-6.4$ & \\
\hline \multirow{2}{*}{$\begin{array}{l}\text { Ovarian } \\
\text { metastasis }\end{array}$} & No & 6.0 & $5.5-6.8$ & 0.5893 \\
\hline & Yes & 10.8 & $5.0-15.9$ & \\
\hline
\end{tabular}

Table 2 continued

\begin{tabular}{|c|c|c|c|c|}
\hline Variable & Category & $\begin{array}{l}\text { Median } \\
\text { survival } \\
\text { (months) }\end{array}$ & $95 \% \mathrm{CI}$ & $p$ value \\
\hline \multicolumn{5}{|c|}{ Healthcare system characteristics } \\
\hline \multirow[t]{14}{*}{ LHIN } & 1 & 6.0 & $3.9-9.1$ & \multirow[t]{14}{*}{0.0108} \\
\hline & 2 & 5.0 & $3.5-8.0$ & \\
\hline & 3 & 6.1 & $3.4-8.6$ & \\
\hline & 4 & 7.3 & $5.1-8.9$ & \\
\hline & 5 & 9.1 & $5.2-13.0$ & \\
\hline & 6 & 6.3 & $4.7-8.3$ & \\
\hline & 7 & 5.8 & $4.9-7.2$ & \\
\hline & 8 & 5.8 & $4.5-7.6$ & \\
\hline & 9 & 7.6 & $5.6-10.2$ & \\
\hline & 10 & 5.2 & $2.4-6.9$ & \\
\hline & 11 & 6.6 & $4.6-10.1$ & \\
\hline & 12 & 3.4 & $2.2-4.8$ & \\
\hline & 13 & 6.7 & $4.3-8.7$ & \\
\hline & 14 & 4.7 & $2.9-18.8$ & \\
\hline \multirow[t]{2}{*}{ Gastrectomy } & No & 4.2 & $3.9-4.7$ & \multirow[t]{2}{*}{$<0.0001$} \\
\hline & Yes & 13.3 & $11.0-14.8$ & \\
\hline \multirow[t]{2}{*}{ Chemotherapy } & No & 3.4 & $3.0-3.9$ & \multirow[t]{2}{*}{$<0.0001$} \\
\hline & Yes & 11.7 & $10.4-12.9$ & \\
\hline \multirow[t]{2}{*}{ Radiotherapy } & No & 4.7 & $4.3-5.1$ & \multirow[t]{2}{*}{$<0.0001$} \\
\hline & Yes & 12.0 & $10.5-13.4$ & \\
\hline \multirow{2}{*}{$\begin{array}{l}\text { High-volume } \\
\text { gastric } \\
\text { cancer specialist } \\
\text { consultation }\end{array}$} & No & 4.3 & $3.9-4.7$ & \multirow[t]{2}{*}{$<0.0001$} \\
\hline & Yes & 11.9 & $10.6-13.4$ & \\
\hline
\end{tabular}

worse prognosis. Healthcare system factors, including treatment, region of residence and consultation with a highvolume gastric cancer specialist, were strong predictors of survival after adjustment for patient- and disease-related factors.

After adjusting for patient and disease characteristics, our results supported other population-based data, leading to the conclusion that gastrectomy, chemotherapy and radiotherapy are associated with improved overall survival compared to patients not undergoing the therapy [8-11]. Although consistent, these results should be interpreted with caution. It has been well documented that treatment selection bias, or a lack of understanding of the decisionmaking behind receipt of a particular modality, likely confounds the association between treatment and survival [22]. Therefore, the treatment strategy a patient undergoes may be more a reflection of the patient's overall health and patient, physician and institution behaviors and preferences. We were unable to determine why some patients did not receive chemotherapy or any of the other treatment modalities. A Cochrane review has provided strong 


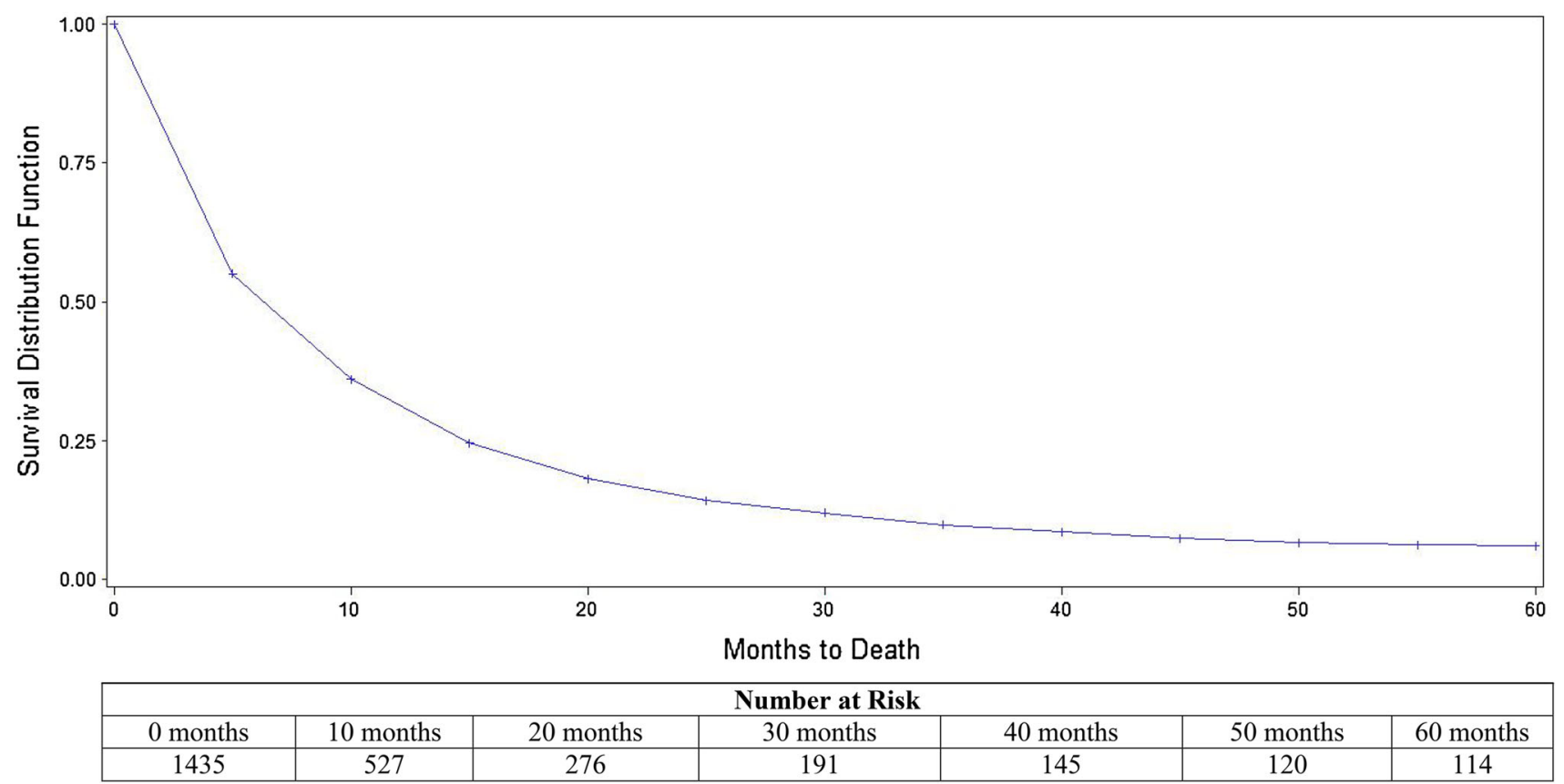

Fig. 2 Overall Kaplan-Meier curve of time from diagnosis to death (from any cause) for metastatic gastric cancer patients in Ontario

evidence of a significant survival benefit for receipt of chemotherapy in comparison with best supportive care alone [23], and ongoing randomized controlled trials are investigating the benefit of surgery in metastatic patients $[24,25]$. Until these results are available, guidelines for treatment decision-making in the metastatic population will remain inconclusive as to the best management strategy $[25,26]$. In the absence of these data, future work understanding the characteristics of patients who receive these therapies will provide further support to clinicians in making treatment decisions.

Two metaanalyses have investigated the prognostic role of surgeon volume in gastric cancer patients undergoing cancer-directed surgery, and both determined a consistent association between higher volume and reduced short-term mortality; the association with long-term outcomes was less clear $[27,28]$. In the metastatic population, the effect of surgeon volume on outcomes was reduced. We explored the possibility that this interaction may be better represented by measuring contact (consultation or treatment) with a high-volume specialist (medical oncologist, surgeon or radiation oncologist), as their treatment is multidisciplinary, and best practice may be the nonreferral to surgery rather than the surgery itself that most impacts long-term outcomes in the metastatic population. This study identified care from a high-volume specialist as being a strongly protective factor, associated with a $15 \%$ reduction in rate of death (95\% CI 0.75-0.98). High surgeon volume has been proposed to represent experience, training and understanding of disease management, and this depth of understanding likely applies across specialties. In the metastatic setting, volume may positively influence longterm outcomes through appropriate supplementary care (not measured in this study), management of symptoms and optimal patient selection for treatment modalities. Further investigation and refinement of our understanding of the role of specialty volume and survival in metastatic cancer are warranted and could provide an understanding of the benefits of centralization of cancer care above and beyond the traditional knowledge of operative outcomes.

This study was limited by its inability to provide an evaluation of the prognostic value of many biologic, pathologic and molecular features of the cancer. Data on such factors as histologic classification, lymphovascular invasion or perineural invasion were missing in more than $50 \%$ of cases, reflecting the large proportion of cases who did not receive surgical management and therefore likely did not receive an in depth pathologic examination. However, given that these features are likely unknown for the majority of patients, this study provides a population-based analysis of practical prognostic factors that will likely be available for prognostication in most metastatic gastric cancer patients in low-incidence countries. In addition, information on performance status was not collected for any of the patients and would likely be a strong predictor of survival.

In the absence of reliable information on molecular, biologic and pathologic tumor factors, primary tumor location, the presence of carcinomatosis, number of metastatic sites, age, sex, geography, treatment modality and receipt of care from a high-volume specialist can be 
Table 3 Bivariate analysis of overall survival using Cox proportional hazards regression

\begin{tabular}{lll}
\hline Variable & Unadjusted & $p$ value \\
& HR & \\
& $(95 \% \mathrm{CI})$ & \\
\hline
\end{tabular}

Patient characteristics

Age (years)

$<65$

$65-74$

$>74$

Sex

Male

Female

Charlson score

0

1

$\geq 2$

Median income

Lowest income

Quintile 2

Quintile 3

Quintile 4

Highest income

Rurality

Urban

Rural

Disease characteristics

Tumor location

Distal stomach

Gastroesophageal junction

Proximal stomach

Middle stomach

Entire stomach

Unknown

Number of metastatic sites

1

2-3

$\geq 4$

Unknown

Distant LN metastasis

No

Yes

Carcinomatosis or ascites

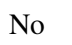

Yes

Liver metastasis

$\begin{array}{ll}\text { No } & \text { Reference } \\ \text { Yes } & 1.26(1.12-1.42)\end{array}$

Retroperitoneal metastasis

$\begin{array}{ll}\text { No } & \text { Reference } \\ \text { Yes } & 1.26(1.03-1.55)\end{array}$

Reference

$<0.0001$

$1.17(1.03-1.34)$

$1.47(1.29-1.67)$

Reference

$0.91(0.82-1.03)$

0.1480

Reference

0.0716

$1.29(1.02-1.61)$

$1.12(0.88-1.43)$

Reference

$0.94(0.80-1.11)$

$0.87(0.74-1.03)$

$0.93(0.79-1.10)$

$0.96(0.80-1.14)$

Reference

$1.20(1.02-1.43)$

Reference

$1.12(0.97-1.28)$

$1.08(0.89-1.32)$

$1.24(1.05-1.46)$

$1.41(1.15-1.71)$

$1.14(0.87-1.49)$

Reference

1.49 (1.33-1.67)

$2.12(1.65-2.71)$

$1.33(0.99-1.81)$

Reference

0.97 (0.87-1.08)

0.5607

Reference

$<0.0001$

1.48 (1.33-1.66)

0.0001
Table 3 continued

\begin{tabular}{lll}
\hline Variable & Unadjusted & $p$ value \\
& HR & \\
& $(95 \% \mathrm{CI})$ & \\
\hline
\end{tabular}

Lung(s) metastasis

No
Yes
Bone(s) metastasis

Reference

0.0172

No

1.24 (1.04-1.49)

Yes

Reference

0.0100

Ovarian metastasis

$\begin{array}{ll}\text { No } & \text { Reference } \\ \text { Yes } & 0.91(0.64-1.29)\end{array}$

0.5900

Healthcare system factors

LHIN

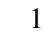

2

$1.30(0.94-1.81)$

0.0130

$1.45(1.04-2.01)$

$1.29(0.92-1.80)$

$1.10(0.82-1.47)$

Reference

$1.32(0.98-1.79)$

$1.19(0.89-1.60)$

$1.11(0.84-1.47)$

$1.03(0.77-1.39)$

$1.34(0.92-1.94)$

$1.24(0.92-1.68)$

$2.12(1.43-3.11)$

$1.36(0.98-1.90)$

$1.09(0.66-1.80)$

Gastrectomy

$\begin{array}{ll}\text { No } & \text { Reference } \\ \text { Yes } & 0.42(0.37-0.47)\end{array}$

$<0.0001$

Chemotherapy

No

Reference

$<0.0001$

Yes

$0.54(0.49-0.61)$

Radiotherapy

$\begin{array}{ll}\text { No } & \text { Reference } \\ \text { Yes } & 0.63(0.56-0.71)\end{array}$

$<0.0001$

High-volume gastric cancer specialist consultation No

Reference

$<0.0001$ Yes

$0.61(0.54-0.68)$

$H R$ hazard ratio, $C I$ confidence interval

considered significant prognostic factors. The consistent identification of these prognostic factors across data sets allows for generalizable prognostication in low-incidence countries. Understanding the added value of molecular and biologic prognostic factors in metastatic gastric cancer in personalizing prognosis and treatment decision-making will require adjustment for these established characteristics. The next steps in precision medicine for metastatic 
Table 4 Multivariate analysis of overall survival using Cox proportional hazards regression

\begin{tabular}{|c|c|c|}
\hline Variable & Overall survival & $p$ value \\
\hline & Adjusted $\mathrm{HR}^{\mathrm{a}}(95 \% \mathrm{CI})$ & \\
\hline \multicolumn{3}{|l|}{ Patient characteristics } \\
\hline Age (per 10 years) & $1.07(1.02-1.10)$ & 0.0036 \\
\hline \multicolumn{3}{|l|}{ Sex } \\
\hline Male & 1.00 (reference) & 0.0008 \\
\hline Female & $0.82(0.73-0.92)$ & \\
\hline \multicolumn{3}{|l|}{ Disease characteristics } \\
\hline \multicolumn{3}{|l|}{ Tumor location } \\
\hline Distal & 1.00 (reference) & 0.0275 \\
\hline Gastroesophageal junction & $1.09(0.94-1.27)$ & \\
\hline Proximal & $0.83(0.68-1.02)$ & \\
\hline Middle & $1.14(0.97-1.35)$ & \\
\hline Entire & $0.99(0.81-1.23)$ & \\
\hline Unknown & $0.80(0.60-1.05)$ & \\
\hline \multicolumn{3}{|c|}{ Presence of carcinomatosis or ascites } \\
\hline No & 1.00 (reference) & $<0.0001$ \\
\hline Yes & $1.61(1.42-1.83)$ & \\
\hline \multicolumn{3}{|l|}{ Number of metastatic sites } \\
\hline 1 & 1.00 (reference) & 0.0007 \\
\hline $2-3$ & $1.17(1.03-1.32)$ & \\
\hline$\geq 4$ & $1.69(1.30-2.20)$ & \\
\hline Unknown & $1.13(0.82-1.55)$ & \\
\hline \multicolumn{3}{|l|}{ Healthcare system factors } \\
\hline \multicolumn{3}{|l|}{ Gastrectomy } \\
\hline No & 1.00 (reference) & $<0.0001$ \\
\hline Yes & $0.43(0.38-0.49)$ & \\
\hline \multicolumn{3}{|l|}{ Chemotherapy } \\
\hline No & 1.00 (reference) & $<0.0001$ \\
\hline Yes & $0.56(0.49-0.64)$ & \\
\hline \multicolumn{3}{|l|}{ Radiotherapy } \\
\hline No & 1.00 (reference) & 0.0001 \\
\hline Yes & $0.77(0.68-0.88)$ & \\
\hline \multicolumn{3}{|c|}{ High-volume gastric cancer specialist } \\
\hline No & 1.00 (reference) & 0.0206 \\
\hline Yes & $0.85(0.75-0.98)$ & \\
\hline \multicolumn{3}{|l|}{ Local health integration network } \\
\hline 1 & $1.03(0.74-1.45)$ & 0.0073 \\
\hline 2 & $1.35(0.97-1.89)$ & \\
\hline 3 & $1.10(0.79-1.55)$ & \\
\hline 4 & $1.03(0.77-1.38)$ & \\
\hline 5 & 1.00 (reference) & \\
\hline 6 & $1.02(0.75-1.39)$ & \\
\hline 7 & $0.88(0.65-1.18)$ & \\
\hline 8 & $0.92(0.69-1.22)$ & \\
\hline 9 & $0.77(0.58-1.04)$ & \\
\hline 10 & $0.96(0.66-1.41)$ & \\
\hline 11 & $0.93(0.69-1.26)$ & \\
\hline 12 & $1.53(1.03-2.28)$ & \\
\hline 13 & $1.16(0.83-1.63)$ & \\
\hline 14 & $0.96(0.58-1.60)$ & \\
\hline
\end{tabular}

${ }^{a}$ Adjusted for all other variables in the model gastric cancer should include the development of a prognostic tool to estimate individualized survival probabilities, incorporating both standard, established prognostic factors and emerging information.

Acknowledgments The authors have no financial interests to disclose. This research is funded by the Canadian Cancer Society (grant no. 019325). Dr. Coburn (Career Scientist Award) has received funding through the Ontario MOHLTC. Dr. Law is supported by the Hanna Family Research Chair in Surgical Oncology. This study was additionally supported by the Institute for Clinical Evaluative Sciences (ICES), which is funded by an annual grant from the Ontario Ministry of Health and Long-Term Care (MOHLTC). The opinions, results and conclusions reported in this paper are those of the authors and are independent from the funding sources. No endorsement by ICES or the Ontario MOHLTC is intended or should be inferred.

\section{References}

1. Parkin DM, Bray F, Ferlay J, Pisani P. Global cancer statistics, 2002. CA Cancer J Clin. 2005;55:74-108.

2. Jemal A, Bray F, Center MM, Ferlay J, Ward E, Forman D. Global cancer statistics. CA Cancer J Clin. 2011;61:69-90.

3. McGhan LJ, Pockaj BA, Gray RJ, Bagaria SP, Wasif N. Validation of the updated 7th edition AJCC TNM staging criteria for gastric adenocarcinoma. J Gastrointest Surg. 2012;16:53-61 discussion 61.

4. Washington $\mathrm{K}$. 7th edition of the AJCC cancer staging manual: stomach. Ann Surg Oncol. 2010;17:3077-9.

5. Canadian Cancer Society's Steering Committee on Cancer Statistics. Canadian cancer statistics 2012. Toronto: Canadian Cancer Society; 2012.

6. SEER cancer statistics review 1975-2008 (Internet). National Cancer Institute: Bethesda, MD; 2011. http://seer.cancer.gov/ statfacts/html/stomach.html.

7. Coburn NG, Lourenco LG, Rossi SE, Gunraj N, Mahar AL, Helyer LK, et al. Management of gastric cancer in ontario. J Surg Oncol. 2010;102:54-63.

8. Smith JK, Hill JS, Ng SC, McDade TP, Shah SA, Tseng JF. Potential benefit of resection for stage IV gastric cancer: a national survey. J Gastrointest Surg. 2010;14:1660-8.

9. Yang D, Hendifar A, Lenz C, Togawa K, Lenz F, Lurje G, et al. Survival of metastatic gastric cancer: significance of age, sex and race/ethnicity. J Gastrointest Oncol. 2011;2:77-84.

10. Shridhar R, Almhanna K, Hoffe SE, Fulp W, Weber J, Chuong MD, et al. Increased survival associated with surgery and radiation therapy in metastatic gastric cancer: a surveillance, epidemiology, and end results database analysis. Cancer. 2013;119(9):1636-42.

11. Kunz PL, Gubens M, Fisher GA, Ford JM, Lichtensztajn DY, Clarke CA. Long-term survivors of gastric cancer: a california population-based study. J Clin Oncol. 2012;30:3507-15.

12. Riley RD, Hayden JA, Steyerberg EW, Moons KG, Abrams K, Kyzas PA, et al. Prognosis research strategy (PROGRESS) 2: prognostic factor research. PLoS Med. 2013;10:e1001380.

13. Robles SC, Marrett LD, Clarke EA, Risch HA. An application of capture-recapture methods to the estimation of completeness of cancer registration. J Clin Epidemiol. 1988;41:495-501.

14. Clarke EA, Marrett LD, Kreiger N. Cancer registration in ontario: a computer approach. In: Jensen OM, Parkin DM, MacLennan R, Muir CS, Skeet RG, editors. Cancer registration principles and methods. Pub No. 95 ed. Lyon, France: IARC; 1991. p. 246-57.

15. Williams JI, Young W. A summary of studies on the quality of health care administrative databases in canada. In: Goel V, 
Williams JI, Anderson GM, Blackstien-Hirsch P, Fooks C, Naylor CD, editors. Patterns of health care in Ontario, The ICES practice atlas. 2nd ed. Ottawa: Canadian Medical Association; 1996.

16. Mackillop WJ, Zhang-Salomons J, Groome PA, Paszat L, Holowaty E. Socioeconomic status and cancer survival in ontario. J ClinOncol. 1997;15:1680-9.

17. Kralj B. Measuring 'rurality' for purposes of health-care planning: An empirical measure for ontario. Ont Med Rev. 2000;67(9):33-52.

18. Charlson ME, Pompei P, Ales KL, MacKenzie CR. A new method of classifying prognostic comorbidity in longitudinal studies: development and validation. J Chronic Dis. 1987;40:373-83.

19. Deyo RA, Cherkin DC, Ciol MA. Adapting a clinical comorbidity index for use with ICD-9-CM administrative databases. J Clin Epidemiol. 1992;45:613-9.

20. Kaplan EL, Meier P. Nonparametric-estimation from incomplete observations. J Am Stat Assoc. 1958;53:457-81.

21. Hess KR. Graphical methods for assessing violations of the proportional hazards assumption in cox regression. Stat Med. 1995;14:1707-23.

22. Mahar AL, Coburn NG, Singh S, Law C, Helyer LK. A systematic review of surgery for non-curative gastric cancer. Gastric Cancer. 2012;15:S125-37.
23. Wagner AD, Unverzagt S, Grothe W, Kleber G, Grothey A, Haerting J, et al. Chemotherapy for advanced gastric cancer. Cochrane Database Syst Rev. 2010;3:CD004064.

24. Fujitani K, Yang HK, Kurokawa Y, do Park J, Tsujinaka T, Park $\mathrm{BJ}$, et al. Randomized controlled trial comparing gastrectomy plus chemotherapy with chemotherapy alone in advanced gastric cancer with a single non-curable factor: Japan clinical oncology group study JCOG 0705 and korea gastric cancer association study KGCA01. Jpn J Clin Oncol. 2008;38:504-6.

25. Kerkar SP, Kemp CD, Duffy A, Kammula US, Schrump DS, Kwong KF, et al. The GYMSSA trial: a prospective randomized trial comparing gastrectomy, metastasectomy plus systemic therapy versus systemic therapy alone. Trials. 2009;10:121.

26. Coburn N, Seevaratnam R, Paszat L, Helyer L, Law C, Swallow $\mathrm{C}$, et al. Optimal management of gastric cancer: results from an international RAND/UCLA expert panel. Ann Surg. 2014;259(1):102-8.

27. Mahar AL, McLeod RS, Kiss A, Paszat L, Coburn NG. A systematic review of the effect of institution and surgeon factors on surgical outcomes for gastric cancer. J Am Coll Surg. 2012;214:860-8.

28. Gruen RL, Pitt V, Green S, Parkhill A, Campbell D, Jolley D. The effect of provider case volume on cancer mortality: systematic review and meta-analysis. CA Cancer $\mathrm{J}$ Clin. 2009;59:192-211. 